\title{
Rice SUT and SWEET Transporters
}

\author{
Zhi Hu ${ }^{1}$, Zhenjia Tang ${ }^{1}$, Yanming Zhang ${ }^{2}$, Liping Niu ${ }^{2}$, Fang Yang ${ }^{2}$, Dechun Zhang ${ }^{3, *}$ and Yibing Hu ${ }^{1, *(D)}$ \\ 1 College of Resources \& Environmental Sciences, Nanjing Agricultural University, Nanjing 210095, China; \\ 2019203047@njau.edu.cn (Z.H.); 2019103102@njau.edu.cn (Z.T.) \\ 2 State Key Laboratory of Hybrid Rice, College of Life Sciences, Wuhan University, Wuhan 430072, China; \\ sklhr@whu.edu.cn (Y.Z.); lipingniu@whu.edu.cn (L.N.); fang-yang@whu.edu.cn (F.Y.) \\ 3 Bio-Technology Research Center, China Three Gorges University, Yichang 443002, China \\ * Correspondence: zhangdechun@ctgu.edu.cn (D.Z.); huyb@njau.edu.cn (Y.H.); Tel.: +86-135-8149-8901 (D.Z.); \\ +86-158-5059-7096 (Y.H.)
}

check for

updates

Citation: Hu, Z.; Tang, Z.; Zhang, Y.; Niu, L.; Yang, F.; Zhang, D.; Hu, Y. Rice SUT and SWEET Transporters. Int. J. Mol. Sci. 2021, 22, 11198.

https://doi.org/10.3390/ijms222011198

Academic Editor: Li-Qing Chen

Received: 11 September 2021

Accepted: 6 October 2021

Published: 18 October 2021

Publisher's Note: MDPI stays neutral with regard to jurisdictional claims in published maps and institutional affiliations.

Copyright: (c) 2021 by the authors. Licensee MDPI, Basel, Switzerland. This article is an open access article distributed under the terms and conditions of the Creative Commons Attribution (CC BY) license (https:/ / creativecommons.org/licenses/by/ $4.0 /)$.

\begin{abstract}
Sugar transporters play important or even indispensable roles in sugar translocation among adjacent cells in the plant. They are mainly composed of sucrose-proton symporter SUT family members and SWEET family members. In rice, 5 and 21 members are identified in these transporter families, and some of their physiological functions have been characterized on the basis of gene knockout or knockdown strategies. Existing evidence shows that most SUT members play indispensable roles, while many SWEET members are seemingly not so critical in plant growth and development regarding whether their mutants display an aberrant phenotype or not. Generally, the expressions of SUT and SWEET genes focus on the leaf, stem, and grain that represent the source, transport, and sink organs where carbohydrate production, allocation, and storage take place. Rice SUT and SWEET also play roles in both biotic and abiotic stress responses in addition to plant growth and development. At present, these sugar transporter gene regulation mechanisms are largely unclear. In this review, we compare the expressional profiles of these sugar transporter genes on the basis of chip data and elaborate their research advances. Some suggestions concerning future investigation are also proposed.
\end{abstract}

Keywords: rice; SUT(C); SWEET; sugar; transporter

\section{Introduction}

Sugar is synthesized in the green tissues of plants and is transported into the sink organs to be stored as starch or other organic compounds, in addition to being metabolized as an energy-producing molecule. Translocation of sugar plays an indispensable role in plant growth and development through controlling carbon partitioning between the stem and grain [1]. Sucrose is the main form of carbohydrates for long-distance transport in plants. It is mainly translocated via the symplastic pathway composed of sieve elementscompanion cells (SE-CC complexes) in the vascular tissues from leaf to flower, seed, and root in higher plants [2,3]. For short-distance transport of sugar, usually between adjacent cells, the apoplastic pathway that depends on membrane-located transporters plays a critical role $[4,5]$. Due to two outstanding discoveries of sugar transporters, namely, SUT(C) (sucrose transporter or carrier) and SWEET (sugar will eventually be exported transporter), in plants achieved in the past 30 years [6,7], the molecular mechanism of sugar apoplastic transport in model plants is beginning to be clarified.

SUT is a class of sucrose-proton symporter only present in plants, probably because sucrose is not produced in animals and microorganisms. As a group of positive sugar transporters, they are extremely important for the acquisition of sucrose from the intercellular apoplast outside of the cell into the cytosol, particularly when no plasmodesma exists between adjacent cells, and a membrane transporter or channel is the only pathway for material exchange. These circumstances include the maternal-filial interface in the seed, the embryo-endosperm interface after the initial stage of seed development, and probably the 
pollen tube-pistil interface during the pollen tube fast growth stage after pollination [8-10]. Moreover, in long-distance transport of sugar via the symplastic pathway, sucrose must be first uploaded into the phloem. The uploading process relies on SUT transporter(s) since very few plasmodesmata exist between the SE-CC complexes and their surrounding cells $[11,12]$. Additionally, during symplastic transport within the phloem, a small portion of sucrose may leak into the apoplast outside of the SE-CC complexes; retrieving this portion of sucrose back to phloem also requires SUT transporter's participation [13,14].

Single-cell organisms only need to assimilate sugar from their environment or produce sugar by themselves if they live on it. However, multicellular organisms also need to export sugar from one cell to another for sugar allocation between cells. Moreover, the efflux of sugar from plant cells is necessary for the symbiont or pathogen's living [15]. In addition, glucose, as the most important molecule for cell metabolism, is universally used from bacteria and archaea to plants and animals. SUT transporters, however, are unable to undertake the transport of glucose due to a lack of substrate compatibility [16]. The identification of SWEET genes revealed how the needs listed above were met in the cell.

In 2010, Chen et al. [7] characterized the first SWEET gene, AtSWEET1, in Arabidopsis. SWEET is a class of passive sugar transporters that transport oligosaccharides such as glucose or sucrose across the membrane along their concentration gradients. This property attributes them with the ability to import or export sugar in or out of a cell. Unlike the plant-specific SUT, SWEETs are present in both plants and animals [17]. Moreover, their homologs in prokaryotes, SemiSWEETs, which also transport sucrose and glucose, were identified in both bacteria and archaea [18]. Recently, a membrane protein of SARS-CoV-2 (QJA17755) was postulated to resemble SemiSWEETs, as the putative protein possesses a triple helix bundle and forms a single three-transmembrane domain [19]. However, sequence alignment showed that the amino-acid identity of the protein with BjSemiSWEET1 [18] and EcSemiSWEET [20] is only about 15.32\%, and no MtN3/slv domain can be identified in the membrane protein of SARS-CoV-2 (http: / / pfam.xfam.org/search/sequence, accessed on 5 October 2021). By contrast, a putative SemiSWEET (DAE96463) of Myoviridae sp. (phage) from Human Metagenome was retrieved by similarity search. It contains a MtN3/slv domain and shows $31.93 \%$ amino-acid identity with BjSemiSWEET1 and EcSemiSWEET. This result indicates that SWEET homologs are distributed much more widely than SUT genes. Given that no SemiSWEET functions have been physiologically characterized to date, a virus SemiSWEET, e.g., DAE96463, may be a new choice for a breakthrough in this area.

In this review, we focus on the two classes of sugar transporters in rice and review advances in the characterization of their physiological roles and molecular mechanisms. Gaining a full understanding of the functions of these sugar transporters is challenging, particularly with respect to gene regulation mechanisms.

\section{Physiological Functions of Rice SUT Sucrose Transporters}

SUTs are intensively investigated in model plants despite the first SUT gene being characterized in Spinach [6]. In rice, only five transporter genes have been identified in the SUT family [21], but much attention has been paid to their physiological functions, particularly OsSUT1. Since its first report in 1997 [22], many roles of the transporter have been documented via Tos17 or T-DNA insertion-mediated heterologous mutants or RNAi/antisense-mediated knockdown lines of OsSUT1. These functions include providing sugar for pollen development, pollen germination and seed germination [23,24], uploading sucrose into the phloem for long-distance transport $[13,25,26]$, and retrieving leaked sucrose from apoplast outside of the SE-CC complex during sucrose long-distance transport [13]. The most important role it plays is probably in seed-filling [27-33], since the CRISPR/Cas9mediated mutation of the gene conferred complete infertility although the mutant plants did not show much difference from the WT control at their vegetative growth stage except for a slightly dwarfed size [34]. This result is generally consistent with the observations that a homozygous ossut1 mutant derived from anther tissue culture [35] and transgenic 
rice lines with antisense OsSUT1 expression did not confer any abnormal phenotype at the vegetative growth stage $[28,36]$.

In higher plants, phloem loading of sucrose can be accomplished either via the apoplastic pathway which depends on membrane-located sucrose transporters or via the symplastic pathway which depends on plasmodesmata between SE-CC complexes and adjacent cells [3,37]. These pathways are usually present in herbaceous plants including crops and trees [14,38]. OsSUT1's sucrose-transport capacity [16,21], localization on the PM of companion cells [34,39], and ability to complement atsut2 [25] support the apoplastic pathway of phloem loading in rice. However, the symplastic pathway of phloem loading was also proposed previously by Kaneko et al. [40] through their observation of the ultrastructure of small vascular bundles in rice seedlings. Considering that knockout or knockdown of OsSUT1 did not impair rice vegetative growth $[28,35,36]$, and other SUT members of rice either belong to different types or have a different expressional pattern from OsSUT1 [41,42], Eom et al. [35] proposed that the apoplastic pathway might not be the primary route for rice phloem loading. Therefore, whether the apoplastic or the symplastic is predominant in rice phloem loading remains an open question [14].

Under normal growth conditions in the paddy field, however, ossut 1 homozygous mutants were infertile due to failed grain-filling [34]. This suggests that the failed reproductive growth in the mutants was resulted from the dysfunction of apoplastic phloem loading undertaken by OsSUT1. This pending issue can probably be reconciled from a new perspective: the apoplastic transport of sucrose assumed by OsSUT1 in the SE-CC complexes is dispensable when the amount of sucrose for phloem loading is minimal at the vegetative growth stage of rice; however, it may be critical when a large amount of sucrose needs to be uploaded into the SE-CC complexes for long-distance transport into grains during the reproductive growth stage.

Compared with OsSUT1, the remaining members of the rice SUT family seem to be less critical since mutants of their encoding genes are generally fertile. However, the production and the growth of these mutants are impaired to different extents (Table 1). OsSUT2 was identified to localize on cell tonoplast; it participates in plant growth, and knockout of OsSUT2 reduced tiller number, plant height, grain weight, and root dry weight of rice [43-45]. OsSUT3 is a protein specifically expressed in pollen, and it may be important for pollen and starch accumulation [46,47]. The plasma membrane-localized OsSUT4 is expressed in the vascular tissue of the embryo and coleoptile in the germinated seed; it is also expressed in glume shells, anthers at the flowering stage, and the aleurone layer of caryopsis at the seed-filling stage [48-50]. Knockout of OsSUT4 dwarfed the mutant rice lines, as well as reduced their tiller number and grain yield [48-50]. OsSUT5 is expressed in the culm, leaf, inflorescence, and caryopsis of rice, but it is predominantly expressed during inflorescence and caryopsis development at the transcriptional level. OsSUT5 was identified to localize on the plasma membrane; knockout of OsSUT5 reduced the rice seed-setting rate and conferred a chalky endosperm of the mutant caryopses [51,52].

Table 1. Rice SUT genes and their physiological functions.

\begin{tabular}{|c|c|c|c|}
\hline Genes & Tissue Expression & Function/Knockout Effect & References \\
\hline OsSUT1 & $\begin{array}{l}\text { Leaf; spikelet; root; endosperm; caryopsis; } \\
\text { rachis/branch }\end{array}$ & $\begin{array}{l}\text { Seed-filling; sucrose phloem loading for } \\
\text { long-distance transport; plant growth; } \\
\text { seed germination; pollen development }\end{array}$ & {$[13,22-36]$} \\
\hline OsSUT2 & $\begin{array}{l}\text { Mesophyll; cross cell; } \\
\text { lateral root; pedicel; seed; germinating seed }\end{array}$ & $\begin{array}{l}\text { Seedling growth; pollen development; } \\
\text { plant growth }\end{array}$ & [43-45] \\
\hline OsSUT3 & Pollen & Pollen development & {$[46,47]$} \\
\hline OsSUT4 & $\begin{array}{c}\text { Leaf; root; anther; pollen; glume; embryo; } \\
\text { caryopsis; spikelet }\end{array}$ & $\begin{array}{l}\text { Reduced plant height and tiller } \\
\text { number; yield loss of the mutants }\end{array}$ & {$[48-50]$} \\
\hline OsSUT5 & Culm; leaf; floret; caryopsis; embryo & $\begin{array}{l}\text { Reduced seed-setting rate and } \\
\text { increased endosperm chalk in the } \\
\text { mutant caryopses; yield loss }\end{array}$ & {$[51,52]$} \\
\hline
\end{tabular}

A comparison of rice SUT gene expressions based on chip data shows that their expressional intensities seem to match the physiological roles played by their gene-encoding 
proteins (Table 2). For example, OsSUT1 is critical for rice development at the reproductive growth stage, and OsSUT1 shows the strongest expression among rice SUT genes, particularly in the stem and the developing caryopsis. The expression of OsSUT2 is weaker than that of OsSUT1 but stronger than that of the remaining SUT genes of rice. Accordingly, the abnormality of OSSUT2 mutants is milder than that of OSSUT1 mutants but greater than that of the remaining rice SUT gene knockout mutants. Moreover, the expressions of rice SUT genes, especially OsSUT1 and OsSUT2, focus on the leaf, stem, and grain (Table 2). These organs are the source, transport, and sink organs of rice, respectively. Notably, all SUT genes except for OsSUT2 show very weak expressions in the root at the transcriptional level. Xu et al. [53] reported that none of the rice SUT genes were expressed in the root, as detected via GUS expression. However, another investigation employing the same method showed that OsSUT1 was expressed in the root of rice shortly after seed germination [34]. Different promoter lengths used for driving GUS expression or different observation times perhaps gave rise to these differences.

Table 2. Expression levels of SUT genes in various rice tissues based on gene chip data (https:// ricexpro.dna.affrc.go.jp/, accessed on 22 August 2021).

\begin{tabular}{|c|c|c|c|c|c|c|c|c|c|c|c|c|}
\hline Gene trans- & Accession & Root & Stem & Leaf-b & Sheath & Inflore & Anther & Pistil & $\mathrm{Le} / \mathrm{Pa}$ & Ovary & Embryo & Endo \\
\hline OsSUT1-2 & AK100027 & 1 & 9 & 7 & 5 & 0 & 0 & 1 & 5 & 7 & 11 & 3 \\
\hline OsSUT1-3 & D87819 & 1 & 9 & 8 & 6 & 0 & 0 & 1 & 6 & 8 & 14 & 4 \\
\hline OsSUT2-1 & AK067030 & 5 & 7 & 5 & 4 & 1 & 1 & 1 & 3 & 2 & 1 & 1 \\
\hline OsSUT2-2 & AB091672 & 3 & 4 & 4 & 2 & 1 & 1 & 1 & 1 & 1 & 1 & 0 \\
\hline OsSUT3 & AB071809 & 0 & 0 & 0 & 0 & 0 & 0 & 0 & 0 & 0 & 0 & 0 \\
\hline OsSUT4-1 & AY137242 & 1 & 1 & 0 & 0 & 0 & 0 & 1 & 1 & 1 & 1 & 0 \\
\hline OsSUT4-2 & AK065430 & 1 & 1 & 0 & 0 & 0 & 1 & 1 & 1 & 1 & 1 & 0 \\
\hline OsSUT5 & AK073105 & 0 & 0 & 0 & 0 & 0 & 1 & 1 & 2 & 1 & 0 & 0 \\
\hline
\end{tabular}

Red squares represent strong expression; brown squares represent medium expression; yellow squares represent weak expression; blue squares represent no or only marginal expression. Numbers in squares represent relative intensities of gene expression. Leaf-b: leaf blade; Infore: inflorescence; Le/Pa: lemma/palea; Endo: endosperm. NA: data not available. Hyphenated and numbered genes denote different transcripts.

Interestingly, Arabidopsis possesses nine SUC members, while the rice SUT family contains five SUT members, although the Arabidopsis genome is only about one-third of the rice genome [21,41,42]. However, both Arabidopsis and rice contain 12 SUT gene transcripts according to a recent investigation [34]. Notably, OsSUT1 possesses at least six alternative splicings of transcripts [34]. As alternative splicing is a way to regulate plant development [54], it probably explains why rice SUTs can assume so many roles in plant growth and development with limited members. Nevertheless, functional characterizations of all transcripts of OsSUT1 and elucidating their regulation mechanisms remain challenging.

\section{Rice SUT Gene Regulations}

Not surprisingly, the expression of rice SUT genes is strictly regulated by various factors in changing environments. In 2012, Siahpoosh [55] reported that modification of OsSUT1 expression regulated the salt response of rice Oryza sativa cv. Taipei 309. This suggests that the sugar transporter gene may participate in the cell's abiotic stress response by adjusting cytosol sugar concentration. Under drought stress, the expression of OsSUT1 was intensified and the expression of OsSUT4 was downregulated significantly [56]. High temperature or heat stress during the seed-filling stage reduced OsSUT1 and starch synthesis-related gene expression and led to earlier ripening and chalky grain $[31,33,56]$. On the other hand, low temperature or chilling treatment also downregulated the expressions of OsSUT1, OsSUT2, and OsSUT4 [50,57]. In addition, the expression of OsSUT1 was reduced in the leaf and grain but increased in the stem under submergence at the ripening stage of rice development [58].

It is easy to understand that $\mathrm{CO}_{2}$ concentration in the environment can affect the sucrose transporter gene's expression [56]. However, the rice SUT gene expressions are also influenced by plant nutritional factors. For example, Chen et al. [59] reported that the deficiency of potassium induced by knockout of OsHAK1 reduced the expressions of OsSUT1, OsSUT2, OsSUT4, and OsSUT5 at both the vegetative and the reproductive growth 
stages of rice. Moreover, iron deficiency inhibited all SUT gene expressions in rice leaf [60]. Mutation of $\mathrm{PHO} 3$ (AtSUT2) in Arabidopsis brought the mutant plant a phenotype of low phosphorus stress $[61,62]$. It is worth waiting to identify the corresponding SUT gene in rice. Nevertheless, this suggests that the plant phosphorus pathway and sucrose transport activity are interlinked. Nitrogen uptake is highly integrated with the availability of sugars [63]. However, it is still not clear whether the rice SUT gene expressions respond to nitrogen form or abundance, although a similar occurrence was identified in crabapple [64].

Interestingly, biotic stress such as insect infections may also affect SUT gene expression. Ibraheem et al. [65] reported that aphid feeding on rice leaf blade vascular bundles caused an upregulation of OsSUT1 expression in xylem parenchyma. In addition, Chang et al. [66] reported that the larval infestation of Cnaphalocrocis medinalis and mechanical wounding induced an upregulation of OsSUT4 expression. If these phenomena can be confirmed, whether this upregulation of SUT gene expression is a response to the drop in sucrose concentration in plant cells caused by insect feeding or the aftermath of the insect's released substance can be investigated. In any case, this process helps the insects acquire more sucrose from the vascular tissue of rice they infected.

Despite that rice SUT gene expressions being influenced by a plethora of environmental factors including biotic and abiotic stresses, the underlying mechanisms are still unclear. In all of the responses of SUT gene expression to various environmental stimuli mentioned above, no transcription factor which directly binds to the promoter sequence of the SUT genes has been identified to date. As a result, no regulation pathway of these SUT genes can be established on the basis of current knowledge. By contrast, concerning the SUT protein's role in rice growth and development, using a yeast one-hybrid assay and EMSA analysis, Bai et al. [67] demonstrated that OsSUT1, 3, and 4 were regulated by a nuclear factor NF-YB1 during rice grain-filling. Knockout of the NF-YB1-encoding gene in rice conferred a chalky endosperm phenotype. This suggests that NF-YB1 works upstream of the SUT genes and is necessary for rice normal grain-filling. Moreover, a recent investigation showed that both OsSUT1 and OsSWEET11, 14 were targeted by OsDOF11, a DNA-binding protein that controlled their expressions [68].

\section{Physiological Functions of Rice SWEETs}

Animals usually contain only one or a few SWEET members in their genomes, while flowering plants generally possess 17-20 members on average, according to investigations of more than 30 plant species [69,70]. SWEETs participate in a variety of plant activities, including seed-filling, nectar secretion, pollen nutrition, and phloem loading and unloading [17,71,72]. In rice, 21 SWEET members have been identified [73]. The first member characterized with a physiological function in seed-filling is OsSWEET4. Knockout mutants of the gene bore almost complete empty caryopses, and a similar phenotype was observed in the gene's homolog mutants of Maize [74]. Later, Ma et al. [75] and Yang et al. [76] reported that knockout of OsSWEET11 impaired grain-filling of the gene's mutants, which demonstrated the essential role of the gene encoding protein in seed-filling. Furthermore, Ma et al. [75] reported that the seed setting rate of the mutants was reduced. Yang et al. [76] reported that the maturation of the gene's mutants was postponed, and double mutation of OsSWEET11 and OsSWEET15 conferred complete infertility (Table 3). A recent investigation [77] confirmed the results of Ma et al. [75] and Yang et al. [76]. Previously, both Chu et al. [78] and Yang et al. [79] reported that OsSWEET11 played a role in rice pollen development via RNAi analysis.

In contrast to the results that knockout of rice SUT genes usually confers aberrant phenotypes (Table 1), some SWEET genes of rice seem dispensable in plant growth and development. Accumulating data show that knockout of OsSWEET14 in different rice varieties did not cause any abnormal phenotype [77,80-82]. Moreover, we mutated OsSWEET1a, OsSWEET14, and OsSWEET5 via CRISPR/Cas9-mediated genome editing in Japonica rice Nipponbare but did not observe any obvious abnormal phenotype [83]. 
From a comparison of the phenotypes of single or double mutants of characterized rice SWEET genes, it seems that OsSWEET4 is the most important among them for rice growth and development, because mutation of the gene seriously affected seed-filling [74]. A less critical gene is probably OsSWEET11, since knockout of the gene significantly affected rice grain-filling [75-77] and knockdown of the gene reduced pollen viability [78, 79]. Double mutation of OSSWEET11 and OSSWEET15 in rice led to complete infertility, although knockout of OsSWEET15 alone did not cause an abnormal phenotype according to Yang et al. [75]. By contrast, double mutants of OsSWEET11 and OsSWEET14 were fertile although they suffered a heavier impairment in seed-filling than the OsSWEET11 single-gene mutants [77]. It seems that the importance of the characterized SWEET genes in rice growth and development conform to the following order: OsSWEET4 > OsSWEET11 $>$ OsSWEET15 > OsSWEET14.

Chip data quantification, as shown in Table 4, indicates that OsSWEET1a, OsSWEET4, OsSWEET11, OsSWEET13, OsSWEET14, OsSWEET15, and OSSWEET16 show relatively strong expressions, with OsSWEET1 $a$ being the strongest among them. Many SWEET genes of rice show weak, marginal, or no expression. Unlike the expression intensities of rice SUT genes, which were generally consistent with the impairments their mutants suffered, OsSWEET1a mutants did not show any aberrant phenotype [83]. By contrast, the knockout and knockdown of OsSWEET4 and OsSWEET11 in rice led to obvious abnormalities [74-79] despite their expressions being weaker than that of OsSWEET1a.

Table 3. Rice SWEET genes and their physiological functions.

\begin{tabular}{cccc}
\hline Genes & Expression Site & Function In/Knockout Affect & References \\
\hline OsSWEET4 & Spikelet; leaf & Seed-filling & {$[74]$} \\
OsSWEET11 & Caryopsis; anther; & Seed-filling; pollen & {$[75-79]$} \\
& development & \\
OsSWEET14 & sheath; pedicel; leaf; pollen development & Seed-filling & {$[77]$} \\
OsSWEET15 & Caryopsis & Seed-filling & {$[76]$} \\
& Caryopsis; pollen; & & \\
\hline
\end{tabular}

Table 4. Expression levels of SWEET genes in various rice tissues based on gene chip data (https://ricexpro.dna.affrc.go.jp/, accessed on 22 August 2021).

\begin{tabular}{|c|c|c|c|c|c|c|c|c|c|c|c|c|}
\hline Gene trans- & Accession & Root & Stem & Leaf-b & Sheath & Inflore & Anther & Pistil & $\mathrm{Le} / \mathrm{Pa}$ & Ovary & Embryo & Endo \\
\hline OsSWEET1a & AK099531 & 25 & 13 & 6 & 14 & 7 & 14 & 4 & 14 & 2 & 10 & 0 \\
\hline OsSWEET1b & AK063475 & 0 & 0 & 7 & 2 & 0 & 0 & 0 & 0 & 0 & 1 & 4 \\
\hline OsSWEET $2 a$ & AK104255 & 1 & 0 & 0 & 0 & 0 & 0 & 0 & 0 & 0 & 0 & 0 \\
\hline OsSWEET $2 b$ & AK059965 & 0 & 0 & 1 & 1 & 0 & 0 & 0 & 0 & 0 & 0 & 0 \\
\hline OsSWEET2C & NA & NA & NA & NA & NA & NA & NA & NA & NA & NA & NA & NA \\
\hline OsSWEET3a & NA & 0 & 0 & 0 & 0 & 0 & 0 & 0 & 0 & 0 & 0 & 0 \\
\hline OsSWEET3b & NA & 0 & 0 & 0 & 0 & 0 & 0 & 0 & 0 & 0 & 0 & 0 \\
\hline OsSWEET4 & AK071676 & 6 & 14 & 8 & 8 & 7 & 5 & 6 & 20 & 7 & 10 & 2 \\
\hline OsSWEET5 & AK069614 & 0 & 0 & 0 & 0 & 0 & 7 & 0 & 0 & 0 & 0 & 0 \\
\hline OsSWEET6a & NA & 1 & 0 & 0 & 0 & 0 & 1 & 0 & 0 & 0 & 0 & 0 \\
\hline OsSWEET6b & AK099440 & 1 & 0 & 0 & 0 & 0 & 1 & 0 & 0 & 0 & 0 & 0 \\
\hline OsSWEET7a & NA & 0 & 0 & 0 & 0 & 0 & 0 & 0 & 0 & 0 & 0 & 0 \\
\hline OsSWEET7b & NA & 0 & 0 & 0 & 0 & 0 & 0 & 0 & 0 & 0 & 0 & 0 \\
\hline OsSWEET7c & NA & NA & NA & NA & NA & NA & NA & NA & NA & NA & NA & NA \\
\hline OsSWEET7e & NA & NA & NA & NA & NA & NA & NA & NA & NA & NA & NA & NA \\
\hline OsSWEET11 & AK106127 & 0 & 3 & 0 & 3 & 6 & 10 & 4 & 12 & 26 & 0 & 15 \\
\hline OsSWEET12 & AK109114 & 0 & 0 & 0 & 0 & 0 & 0 & 0 & 0 & 0 & 0 & 0 \\
\hline OsSWEET13 & CI437556 & 3 & 12 & 6 & 14 & 0 & 0 & 0 & 5 & 3 & 0 & 0 \\
\hline OsSWEET14 & AK101913 & 4 & 1 & 1 & 2 & 0 & 0 & 0 & 0 & 2 & 6 & 0 \\
\hline OsSWEET15 & AK103266 & 0 & 4 & 0 & 1 & 1 & 2 & 1 & 6 & 9 & 4 & 8 \\
\hline OsSWEET16 & CI149956 & 0 & 4 & 1 & 1 & 0 & 0 & 0 & 3 & 0 & 1 & 0 \\
\hline
\end{tabular}

Red squares represent strong expression; brown squares represent medium expression; yellow squares represent weak expression; blue squares represent no or only marginal expression. Numbers in squares represent relative intensities of gene expression. Leaf-b: leaf blade; Infore: inflorescence; Le/Pa: lemma/palea; Endo: endosperm. NA: data not available. Hyphenated and numbered genes denote different transcripts.

As both SUT and SWEET can transport sugar across the membranes, it is interesting to determine which will have the predominant role when the sugar concentration outside of a cell is higher than that of the cytosol. Both SUTs and SWEETs can achieve this function 
under these circumstances. Comparatively, SWEET might be the economic choice because it does not consume proton potential which needs energy input during the transport process. The protein that will be recruited to do the job probably depends on which gene's expression is induced under the circumstances. As low-affinity and $\mathrm{pH}$-independent sugar transporter-encoding genes [84], SWEETs are usually expressed strongly in rice tissues with abundant sugar to transport under normal growth conditions, as observed in Table 4, except for OsSWEET1a. Therefore, it is not surprising that SWEET proteins usually act as sugar efflux transporters.

\section{SWEETs Interaction with Pathogens}

In addition to the roles they play in plant growth and development, some members in clade III of the rice SWEET family are deeply involved in plant-pathogen interactions. Due to their dual property of being able to transport sugar in and out of a cell across the plasm membrane, three genes from clade III of the rice SWEET family are liable to be hijacked by pathogens such as Xanthomonas oryzae pv. Oryzae (Xoo) and Rhizoctonia solani for their propagation $[85,86]$.

Xoo is a widespread vascular pathogen of rice bacterial blight that prevails in Asia and Africa [86]. It causes severe yield loss of rice and seriously endangers food security. By targeting effector-binding elements (EBEs) in the promoters of susceptible SWEET genes with transcription activator-like effectors (TALe), Xoo induces SWEET gene expression to obtain sugar from the host cell for its propagation [7]. Currently identified TALes of Xoo can be classified into six types: PthXo1, PthXo2, PthXo3, AvrXa7, Tal F, and Tal C. Xoo-susceptible SWEET genes contain one or more of these TALe targets, i.e., EBEs, in their promoter regions [86]. The EBEs in the promoter regions of OsSWEET11 and OsSWEET13 are targeted by PthXo1 and PthXo2, respectively [86-89]. However, OsSWEET14 is targeted by one or more TALes including PthXo3, AvrXa7, Tal F, and Tal C [86,89-95].

The first case revealing the relationship between a SWEET gene and Xoo was Xa13 (OsSWEET11), which is a Xoo-related resistance locus in the recessive $x a 13$ rice strain $[79,96]$. Later, it was identified that rice $x a 13$ recessive resistance to bacterial blight can be defeated by induction of the disease-susceptible gene Os-11N3 (OsSWEET14) [88].

Since four of the six major TAL effector (TALe) types of Xoo strains from different geographic origins and genetic lineages target its promoter [86,89-95], OsSWEET14 is the pivotal target gene of all characterized Xoo varieties from Africa and most varieties from Asia. Thus, many efforts to avoid Xoo infection have focused on the regulation of this gene's expression. Recently, using CRISPR/Cas9-mediated genome editing based on an OsSWEET11 resistant allele cultivar, Oliva et al. [86] demonstrated that mutation of the EBEs in the promoter regions of OSSWEET13 and OsSWEET14 conferred a broad-spectrum resistance of rice to Xoo variety infections. This work highlights the promising feature of this strategy in combating Xoo infections.

Naturally occurring Xoo-resistant rice varieties are often derived from spontaneous mutation of the EBEs in the susceptible gene's promoters. Similar to OsSWEET11 and OsSWEET13, OsSWEET14 also has a Xoo-resistant allele [95]. These Xoo-resistant alleles are valuable germplasms for breeding. As mentioned above, at least five independent investigations revealed that knockout of OsSWEET14 in different rice cultivars (Kitaake; Zhonghua 11; Nipponbare) did not impair rice growth and yield [77,80-83]. Future breeding efforts to obtain Xoo-resistant rice cultivars based on OsSWEET14 mutants naturally occurring or edited in the coding region of the gene may be another choice, since the existing Xoo-resistant alleles are usually derived from EBE mutations of the susceptible genes. An additional advantage of the alternative is that even the adaption of Xoo TALes cannot control the target gene for sugar acquisition.

\section{SWEETs Response to Abiotic Stress and Regulation}

The response of SWEET genes to abiotic stress was first identified in Arabidopsis [97,98]. More detailed information about the role of SWEET genes in response to abiotic stress such 
as cold, high temperature, drought, and salinity in a variety of higher plants can be found in an excellent review by Breia et al. [70]. Very recently, Mathan et al. [99] reported that the expressions of OsSWEET13 and OsSWEET15 were intensified at both the transcriptional and the translational levels in response to salt and drought stresses. It will not be surprising if future investigations reveal that rice sugar transporter genes are involved in all kinds of sugar-associated activities.

The regulation mechanism of the expression of SWEET genes by pathogen TALes is relatively clear. Moreover, rice NAC transcription factors ONAC127/129 specifically bind the promoter of OsSWEET4, as revealed by ChIP-seq analysis [100]. As mentioned above, both OsSUT1 and OsSWEET11, 14 are targeted by a DNA-binding protein OsDOF11 [68]. These facts indicate that a TF protein can simultaneously regulate the expressions of both SUT and SWEET genes, and these genes may be controlled by different factors. This also suggests that the regulation of sugar transporter genes is multifactorial and complex.

\section{Concluding Remarks}

In rice, both SUT and SWEET play conspicuous roles in assimilate translocation. They also participate in biotic and abiotic stress responses. Nevertheless, the physiological functions of most members of the SWEET family are not yet characterized. Moreover, the regulation mechanisms of these sugar transporter genes are only partially or beginning to be elucidated. In particular, the function of these transporters in sugar sensing [101] is an interesting field waiting to be addressed. A comprehensive understanding of their roles in planta may help to increase crop yield and quality in the future.

Funding: This research was funded by Open Research Fund of State Key Laboratory of Hybrid Rice, Wuhan University, grant number KF202104.

Institutional Review Board Statement: Not applicable.

Informed Consent Statement: Not applicable.

Acknowledgments: We apologize to those colleagues whose research we were unable to cite or discuss due to the length limitations of this review.

Conflicts of Interest: The authors declare no conflict of interest. The funders had no role in the design of the study; in the collection, analyses, or interpretation of data; in the writing of the manuscript, or in the decision to publish the results.

\section{Abbreviation}

CRISPR-Cas9 Clustered Regularly Interspaced Short Palindromic Repeats-Cas9

\section{References}

1. Mathan, J.; Singh, A.; Ranjan, A. Sucrose transport and metabolism control carbon partitioning between stem and grain in rice. J. Exp. Bot. 2021, 72, 4355-4372. [CrossRef]

2. Braun, D.M.; Wang, L.; Ruan, Y.L. Understanding and manipulating sucrose phloem loading, unloading, metabolism, and signalling to enhance crop yield and food security. J. Exp. Bot. 2014, 65, 1713-1735. [CrossRef]

3. Turgeon, R. The role of phloem loading reconsidered. Plant Physiol. 2010, 152, 1817-1823. [CrossRef]

4. Zhang, W.H.; Zhou, Y.; Dibley, K.E.; Tyerman, S.D.; Furbank, R.T.; Patrick, J.W. Review: Nutrient loading of developing seeds. Funct. Plant Biol. 2007, 34, 314-331. [CrossRef] [PubMed]

5. Kühn, C.; Grof, C.P. Sucrose transporters of higher plants. Curr. Opin. Plant Biol. 2010, 13, 288-298. [CrossRef] [PubMed]

6. Riesmeier, J.W.; Willmitzer, L.; Frommer, W.B. Isolation and characterization of a sucrose carrier cDNA from spinach by functional expression in yeast. EMBO J. 1992, 11, 4705-4713. [CrossRef] [PubMed]

7. Chen, L.Q.; Hou, B.H.; Lalonde, S.; Takanaga, H.; Hartung, M.L.; Qu, X.Q.; Guo, W.J.; Kim, J.G.; Underwood, W.; Chaudhuri, B.; et al. Sugar transporters for intercellular exchange and nutrition of pathogens. Nature 2010, 468, 527-532. [CrossRef]

8. Thorne, J.H. Phloem unloading of $C$ and N assimilates in developing seeds. Annu. Rev. Plant Physiol. 1985, 36, 317-343. [CrossRef]

9. Stadler, R.; Lauterbach, C.; Sauer, N. Cell-to-cell movement of green fluorescent protein reveals post-phloem transport in the outer integument and identifies symplastic domains in Arabidopsis seeds and embryos. Plant Physiol. 2005, 139, 701-712. [CrossRef]

10. Werner, D.; Gerlitz, N.; Stadler, R. A dual switch in phloem unloading during ovule development in Arabidopsis. Protoplasma 2011, 248, 225-235. [CrossRef] 
11. Geiger, D.R.; Giaquinta, R.T.; Sovonick, S.A.; Fellows, R.J. Solute distribution in sugar beet leaves in relation to phloem loading and translocation. Plant Physiol. 1973, 52, 585-589. [CrossRef] [PubMed]

12. Evert, R.F.; Eschrich, W.; Heyser, W. Leaf structure in relation to solute transport and phloem loading in Zea mays L. Planta 1978, 138, 279-294. [CrossRef] [PubMed]

13. Scofield, G.N.; Hirose, T.; Aoki, N.; Furbank, R.T. Involvement of the sucrose transporter, OsSUT1, in the long-distance pathway for assimilate transport in rice. J. Exp. Bot. 2007, 58, 3155-3169. [CrossRef] [PubMed]

14. Julius, B.T.; Leach, K.A.; Tran, T.M.; Mertz, R.A.; Braun, D.M. Sugar transporters in plants: New insights and discoveries. Plant Cell Physiol. 2017, 58, 1442-1460. [CrossRef] [PubMed]

15. Chen, L.Q. SWEET sugar transporters for phloem transport and pathogen nutrition. New Phytol. 2014, 201, 1150-1155. [CrossRef]

16. Sun, Y.; Reinders, A.; LaFleur, K.R.; Mori, T.; Ward, J.M. Transport activity of rice sucrose transporters OsSUT1 and OsSUT5. Plant Cell Physiol. 2010, 51, 114-122. [CrossRef] [PubMed]

17. Chen, L.Q.; Cheung, L.S.; Feng, L.; Tanner, W.; Frommer, W.B. Transport of sugars. Annu. Rev. Biochem. 2015, 84, 865-894. [CrossRef] [PubMed]

18. Xuan, Y.; Hu, Y.; Chen, L.; Sosso, D.; Ducat, D.C.; Hou, B.; Frommer, W.B. Functional role of oligomerization for bacterial and plant SWEET sugar transporter family. Proc. Natl. Acad. Sci. USA 2013, 110, E3685-E3694. [CrossRef]

19. Thomas, S. The structure of the membrane protein of SARS-CoV-2 resembles the sugar transporter SemiSWEET. Pathog. Immun. 2020, 5, 342-363. [CrossRef]

20. Lee, Y.; Nishizawa, T.; Yamashita, K.; Ishitani, R.; Nureki, O. Structural basis for the facilitative diffusion mechanism by SemiSWEET transporter. Nat. Commun. 2015, 6, 6112. [CrossRef]

21. Aoki, N.; Hirose, T.; Scofield, G.N.; Whitfeld, P.R.; Furbank, R.T. The sucrose transporter gene family in rice. Plant Cell Physiol. 2003, 44, 223-232. [CrossRef]

22. Hirose, T.; Imaizumi, N.; Scofield, G.N.; Furbank, R.T.; Ohsugi, R. cDNA cloning and tissue-specific expression of a gene for sucrose transporter from rice (Oryza sativa L.). Plant Cell Physiol. 1997, 38, 1389-1396. [CrossRef]

23. Hirose, T.; Zhang, Z.; Miyao, A.; Hirochika, H.; Ohsugi, R.; Terao, T. Disruption of a gene for rice sucrose transporter, OsSUT1, impairs pollen function but pollen maturation is unaffected. J. Exp. Bot. 2010, 61, 3639-3646. [CrossRef]

24. Scofield, G.N.; Aoki, N.; Hirose, T.; Takano, M.; Jenkins, C.L.; Furbank, R.T. The role of the sucrose transporter, OsSUT1, in germination and early seedling growth and development of rice plants. J. Exp. Bot. 2007, 58, 483-495. [CrossRef]

25. Eom, J.S.; Nguyen, C.D.; Lee, D.W.; Lee, S.K.; Jeon, J.S. Genetic complementation analysis of rice sucrose transporter genes in Arabidopsis SUC2 mutant atsuc2. J. Plant Biol. 2016, 59, 231-237. [CrossRef]

26. Matsukura, C.; Saitoh, T.; Hirose, T.; Ohsugi, R.; Perata, P.; Yamaguchi, J. Sugar uptake and transport in rice embryo. Expression of companion cell-specific sucrose transporter (OsSUT1) induced by sugar and light. Plant Physiol. 2000, 124, 85-94. [CrossRef]

27. Furbank, R.T.; Scofield, G.N.; Hirose, T.; Wang, X.D.; Patrick, J.; Offler, C.E. Cellular localization and function of a sucrose transporter OsSUT1 in developing rice seeds. Aust. J. Plant Physiol. 2001, 28, 1187-1196.

28. Scofield, G.N.; Hirose, T.; Gaudron, J.A.; Furbank, R.T.; Upadhyaya, N.M.; Ohsugi, R. Antisense suppression of the rice sucrose transporter gene, OsSUT1, leads to impaired grain filling and germination but does not affect photosynthesis. Funct. Plant Biol. 2002, 29, 815-826. [CrossRef]

29. Ishibashi, Y.; Okamuraa, K.; Miyazakia, M.; Phana, T.; Yuasaa, T.; Iwaya-Inouea, M. Expression of rice sucrose transporter gene OsSUT1 in sink and source organs shaded during grain filling may affect grain yield and quality. Environ. Exp. Bot. 2014, 97, 49-54. [CrossRef]

30. Ishimaru, T.; Ida, M.; Hirose, S.; Shimamura, S.; Masumura, T.; Nishizawa, N.K.; Nakazono, M.; Kondo, M. Laser microdissectionbased gene expression analysis in the aleurone layer and starchy endosperm of developing rice caryopses in the early storage phase. Rice 2015, 8, 22. [CrossRef]

31. Phan, T.T.T.; Ishibashi, Y.; Miyazaki, M.; Tran, H.T.; Okamura, K.; Tanaka, S.; Nakamura, J.; Yuasa, T.; Iwaya-Inoue, M. High temperature-induced repression of the rice sucrose transporter (OsSUT1) and starch synthesis-related genes in sink and source organs at milky ripening stage causes chalky grains. J. Agro. Crop. Sci. 2013, 199, 178-188. [CrossRef]

32. Hirose, T.; Takano, M.; Terao, T. Cell wall invertase in developing rice caryopsis: Molecular cloning of OsCIN1 and analysis of its expression in relation to its role in grain filling. Plant Cell Physiol. 2002, 43, 452-459. [CrossRef]

33. Miyazaki, M.; Araki, M.; Okamura, K.; Ishibashi, Y.; Yuasa, T.; Iwaya-Inoue, M. Assimilate translocation and expression of sucrose transporter, OsSUT1, contribute to high-performance ripening under heat stress in the heat-tolerant rice cultivar Genkitsukushi. J. Plant Physiol. 2013, 170, 1579-1584. [CrossRef]

34. Wang, X.; Liu, X.; Hu, Z.; Bao, S.; Xia, H.; Feng, B.; Ma, L.; Zhao, G.; Zhang, D.; Hu, Y. Essentiality for rice fertility and alternative splicing of OsSUT1. Plant Sci. 2021. [CrossRef]

35. Eom, J.S.; Choi, S.B.; Ward, J.M.; Jeon, J.S. The mechanism of phloem loading in rice (Oryza sativa). Mol. Cells 2012, 33, 431-438. [CrossRef]

36. Ishimaru, K.; Hirose, T.; Aoki, N.; Takahashi, S.; Ono, K.; Yamamoto, S.; Wu, J.; Saji, S.; Baba, T.; Ugaki, M.; et al. Antisense expression of a rice sucrose transporter OsSUT1 in rice (Oryza sativa L.). Plant Cell Physiol. 2001, 42, 1181-1185. [CrossRef]

37. Turgeon, R.; Medville, R. The absence of phloem loading in willow leaves. Proc. Natl. Acad. Sci. USA 1998, 95, 12055-12060. [CrossRef] 
38. Liesche, J. Sucrose transporters and plasmodesmal regulation in passive phloem loading. J. Integr. Plant Biol. 2017, 59, 311-321. [CrossRef]

39. Sun, Y.; Lin, Z.; Reinders, A.; Ward, J.M. Functionally important amino acids in rice sucrose transporter OsSUT1. Biochemistry 2012, 51, 3284-3291. [CrossRef]

40. Kaneko, M.; Chonan, N.; Matsuda, T.; Kawahara, H. Ultrastructure of the small vascular bundles and transfer pathways for photosynthate in the leaves of the rice plant. Jpn. J. Crop. Sci. 1980, 49, 42-50. [CrossRef]

41. Sauer, N. Molecular physiology of higher plant sucrose transporters. FEBS Lett. 2007, 581, 2309-2317. [CrossRef]

42. Reinders, A.; Sivitz, A.B.; Ward, J.M. Evolution of plant sucrose uptake transporters. Front. Plant Sci. 2012, 3, 22. [CrossRef]

43. Eom, J.S.; Cho, J.I.; Reinders, A.; Lee, S.W.; Yoo, Y.; Tuan, P.Q.; Choi, S.B.; Bang, G.; Park, Y.I.; Cho, M.H.; et al. Impaired function of the tonoplast-localized sucrose transporter in rice, OsSUT2, limits the transport of vacuolar reserve sucrose and affects plant growth. Plant Physiol. 2011, 157, 109-119. [CrossRef]

44. Siao, W.; Chen, J.Y.; Hsiao, H.H.; Chung, P.; Wang, S.J. Characterization of OsSUT2 expression and regulation in germinating embryos of rice seeds. Rice 2011, 4, 39-49. [CrossRef]

45. Ngampanya, B.; Takeda, T.; Sonoda, Y.; Narangajavana, J.; Yamaguchi, J. Characterization of OsSUT2 cDNA expressed before flowering stage. Rice Genet. Newslett. 2002, 19, 49-51.

46. Li, D.D.; Li, J.; Luan, Y.F.; Zhang, C.L.; Xu, R.C.; Lv, D.; Tan, Y.L.; Tan, X.L. Cloning and expression analysis of OsSUT3 gene promoter from Oryza sativa. Mol. Plant Breed. 2018, 16, 7225-7233. (In Chinese)

47. Li, D.; Xu, R.; Lv, D.; Zhang, C.; Yang, H.; Zhang, J.; Wen, J.; Li, C.; Tan, X. Identification of the core pollen-specific regulation in the rice OsSUT3 promoter. Int. J. Mol. Sci. 2020, 21, 1909. [CrossRef]

48. Li, M.; Wang, G.; Wu, Y.; Ren, Y.; Li, G.; Liu, Z.; Ding, Y.; Ceng, L. Function analysis of sucrose transporter OsSUT4 in sucrose transport in rice. Chin. J. Rice Sci. 2020, 34, 491-498. (In Chinese)

49. Yue, M.M. Functional Analysis of a Rice Sucrose Transporter OsSUT4; Shandong Agricultural University: Tai'an, China, 2020. (In Chinese)

50. Chung, P.; Hsiao, H.H.; Chen, H.J.; Chang, C.W.; Wang, S.J. Influence of temperature on the expression of the rice sucrose transporter 4 gene, OsSUT4, in germinating embryos and maturing pollen. Acta Physiol. Plant. 2014, 36, 217-229. [CrossRef]

51. Du, L. Molecular Regulation of OsSUT on Rice Filling Physiology; Fujian Agricultural \& Forestry University: Fuzhou, China, 2010. (In Chinese)

52. Zhang, Y.; Bao, S.; Tang, Z.; Wang, X.; Yang, F.; Zhang, D.; Hu, Y. Function of sucrose transporter OsSUT5 in rice pollen development and seed setting. Sci. Agric. Sin. 2021, 55, 3369-3380. (In Chinese)

53. Xu, L.H.; Xiao, L.Y.; Xiao, Y.N.; Peng, D.L.; Xiao, X.Q.; Huang, W.K.; Gheysen, G.; Wang, G.F. Plasmodesmata play pivotal role in sucrose supply to Meloidogyne graminicola-caused giant cells in rice. Mol. Plant Pathol. 2021, 22, 539-550. [CrossRef]

54. Baralle, F.E.; Giudice, J. Alternative splicing as a regulator of development and tissue identity. Nat. Rev. Mol. Cell Biol. 2017, 7, 437-451. [CrossRef]

55. Siahpoosh, M.R.; Sanchez, D.H.; Schlereth, A.; Scofield, G.N.; Furbank, R.T.; van Dongen, J.T.; Kopka, J. Modification of OsSUT1 gene expression modulates the salt response of rice Oryza sativa cv. Taipei 309. Plant Sci. 2012, 182, 101-111. [CrossRef]

56. Xu, Q.; Chen, S.; Yunjuan, R.; Chen, S.; Liesche, J. Regulation of sucrose transporters and phloem loading in response to environmental cues. Plant Physiol. 2018, 176, 930-945. [CrossRef]

57. Takahashi, S.; Meguro-Maoka, A.; Yoshida, M. Analysis of sugar content and expression of sucrose transporter genes (OsSUTs) in rice tissues in response to a chilling temperature. Jpn. Agric. Res. Q. 2017, 51, 137-146. [CrossRef]

58. Lee, H.S.; Hwang, W.H.; Jeong, J.H.; Ahn, S.H.; Baek, J.S.; Jeong, H.Y.; Park, H.K.; Ku, B.I.; Yun, J.T.; Lee, G.H.; et al. Analysis of the distribution of assimilation products and the characteristics of transcriptomes in rice by submergence during the ripening stage. BMC Genom. 2019, 20, 18. [CrossRef]

59. Chen, G.; Zhang, Y.; Ruan, B.; Guo, L.; Zeng, D.; Gao, Z.; Zhu, L.; Hu, J.; Ren, D.; Yu, L.; et al. OsHAK1 controls the vegetative growth and panicle fertility of rice by its effect on potassium-mediated sugar metabolism. Plant Sci. 2018, 274, 261-270. [CrossRef]

60. Chen, P.F.; Chen, L.; Jiang, Z.R.; Wang, G.P.; Wang, S.H.; Ding, Y.F. Sucrose is involved in the regulation of iron deficiency responses in rice (Oryza sativa L.). Plant Cell Rep. 2018, 37, 789-798. [CrossRef]

61. Zakhleniuk, O.V.; Raines, C.A.; Lloyd, J.C. pho3: A phosphorus-deficient mutant of Arabidopsis thaliana (L.). Heynh. Planta 2001, 212, 529-534. [CrossRef]

62. Lloyd, J.C.; Zakhleniuk, O.V. Responses of primary and secondary metabolism to sugar accumulation revealed by microarray expression analysis of the Arabidopsis mutant, pho3. J. Exp. Bot. 2004, 55, 1221-1230. [CrossRef]

63. Ruffel, S.; Gojon, A.; Lejay, L. Signal interactions in the regulation of root nitrate uptake. J. Exp. Bot. 2014, 65, 5509-5517. [CrossRef]

64. Zhang, L.; Sun, S.; Liang, Y.; Li, B.; Ma, S.; Wang, Z.; Ma, B.; Li, M. Nitrogen levels regulate sugar metabolism and transport in the shoot tips of crabapple plants. Front. Plant Sci. 2021, 12, 626149. [CrossRef] [PubMed]

65. Ibraheem, O.; Botha, C.E.; Bradley, G.; Dealtry, G.; Roux, S. Rice sucrose transporter1 (OsSUT1) up-regulation in xylem parenchyma is caused by aphid feeding on rice leaf blade vascular bundles. Plant Biol. 2014, 16, 783-791. [CrossRef]

66. Chang, Y.A.; Dai, N.C.; Chen, H.J.; Tseng, C.H.; Huang, S.T.; Wang, S.J. Regulation of rice sucrose transporter 4 gene expression in response to insect herbivore chewing. J. Plant Interact. 2019, 14, 525-532. [CrossRef] 
67. Bai, A.N.; Lu, X.D.; Li, D.Q.; Liu, J.X.; Liu, C.M. NF-YB1-regulated expression of sucrose transporters in aleurone facilitates sugar loading to rice endosperm. Cell Res. 2016, 25, 384-388. [CrossRef] [PubMed]

68. Wu, Y.; Lee, S.K.; Yoo, Y.; Wei, J.; Kwon, S.Y.; Lee, S.W.; Jeon, J.S.; An, G. Rice transcription factor OsDOF11 modulates sugar transport by promoting expression of sucrose transporter and SWEET genes. Mol. Plant 2018, 11, 833-845. [CrossRef]

69. Gupta, P.K. SWEET Genes for Disease Resistance in Plants. Trends Genet. 2020, 36, 901-904. [CrossRef]

70. Breia, R.; Conde, A.; Badim, H.; Fortes, A.M.; Gerós, H.; Granell, A. Plant SWEETs: From sugar transport to plant-pathogen interaction and more unexpected physiological roles. Plant Physiol. 2021, 186, 836-852. [CrossRef]

71. Kim, J.Y.; Loo, E.P.; Pang, T.Y.; Lercher, M.; Frommer, W.B.; Wudick, M.M. Cellular export of sugars and amino acids: Role in feeding other cells and organisms. Plant Physiol. 2021, 00, 1-23.

72. Eom, J.S.; Chen, L.Q.; Sosso, D.; Julius, B.T.; Lin, I.W.; Qu, X.Q.; Braun, D.M.; Frommer, W.B. SWEETs, transporters for intracellular and intercellular sugar translocation. Curr. Opin. Plant Biol. 2015, 25, 53-62. [CrossRef]

73. Yuan, M.; Zhao, J.; Huang, R.; Li, X.; Xiao, J.; Wang, S. Rice MtN3/saliva/SWEET gene family: Evolution, expression profiling, and sugar transport. J. Integr. Plant Biol. 2014, 56, 559-570. [CrossRef] [PubMed]

74. Sosso, D.; Luo, D.; Li, Q.B.; Sasse, J.; Yang, J.; Gendrot, G.; Suzuki, M.; Koch, K.E.; McCarty, D.R.; Chourey, P.S.; et al. Seed filling in domesticated maize and rice depends on SWEET-mediated hexose transport. Nat. Genet. 2015, 47, 1489-1493. [CrossRef]

75. Ma, L.; Zhang, D.; Miao, Q.; Yang, J.; Xuan, Y.; Hu, Y. Essential role of sugar transporter OsSWEET11 during the early stage of rice grain filling. Plant Cell Physiol. 2017, 58, 863-873. [CrossRef]

76. Yang, J.; Luo, D.; Yang, B.; Frommer, W.B.; Eom, J.S. SWEET11 and 15 as key players in seed filling in rice. New Phytol. 2018, 218, 604-615. [CrossRef]

77. Fei, H.; Yang, Z.; Lu, Q.; Wen, X.; Zhang, Y.; Zhang, A.; Lu, C. OsSWEET14 cooperates with OsSWEET11 to contribute to grain filling in rice. Plant Sci. 2021, 306, 110851. [CrossRef]

78. Chu, Z.; Yuan, M.; Yao, J.; Ge, X.; Yuan, B.; Xu, C.; Li, X.; Fu, B.; Li, Z.; Bennetzen, J.L.; et al. Promoter mutations of an essential gene for pollen development result in disease resistance in rice. Genes Dev. 2006, 20, 1250-1255. [CrossRef]

79. Yang, B.; Sugio, A.; White, F.F. Os8N3 is a host disease-susceptibility gene for bacterial blight of rice. Proc. Natl. Acad. Sci. USA 2006, 103, 10503-10508. [CrossRef] [PubMed]

80. Kim, P.; Xue, C.Y.; Song, H.D.; Gao, Y.; Feng, L.; Li, Y.; Xuan, Y.H. Tissue-specific activation of DOF11 promotes rice resistance to sheath blight disease and increases grain weight via activation of SWEET14. Plant Biotechnol. J. 2021, 19, 409-411. [CrossRef]

81. Eom, J.S.; Luo, D.; Atienza-Grande, G.; Yang, J.; Ji, C.; Thi Luu, V.; Huguet-Tapia, J.C.; Char, S.N.; Liu, B.; Nguyen, H.; et al. Diagnostic kit for rice blight resistance. Nat. Biotechnol. 2019, 37, 1372-1379. [CrossRef]

82. Zeng, X.; Luo, Y.; Vu, N.T.Q.; Shen, S.; Xia, K.; Zhang, M. CRISPR/Cas9-mediated mutation of OsSWEET14 in rice cv. Zhonghua11 confers resistance to Xanthomonas oryzae pv. oryzae without yield penalty. BMC Plant Biol. 2020, 20, 313. [CrossRef] [PubMed]

83. Ma, L.; Hu, Y.; (College of Resources \& Environmental Sciences, Nanjing Agricultural University, Nanjing, China). Personal communication, 2017.

84. Chen, L.Q.; Qu, X.Q.; Hou, B.H.; Sosso, D.; Osorio, S.; Fernie, A.R.; Frommer, W.B. Sucrose efflux mediated by SWEET proteins as a key step for phloem transport. Science 2012, 335, 207-211. [CrossRef]

85. Gao, Y.; Zhang, C.; Han, X.; Wang, Z.Y.; Ma, L.; Yuan, D.P.; Wu, J.N.; Zhu, X.F.; Liu, J.M.; Li, D.P.; et al. Inhibition of OsSWEET11 function in mesophyll cells improves resistance of rice to sheath blight disease. Mol. Plant Pathol. 2018, 19, 2149-2161. [CrossRef]

86. Oliva, R.; Ji, C.; Atienza-Grande, G.; Huguet-Tapia, J.C.; Perez-Quintero, A.; Li, T.; Eom, J.S.; Li, C.; Nguyen, H.; Liu, B.; et al. Broad-spectrum resistance to bacterial blight in rice using genome editing. Nat. Biotechnol. 2019, 37, 1344-1350. [CrossRef]

87. Liu, Q.; Yuan, M.; Zhou, Y.A.N.; Li, X.; Xiao, J.; Wang, S. A paralog of the MtN3/saliva family recessively confers race-specific resistance to Xanthomonas oryzae in rice. Plant Cell Environ. 2011, 34, 1958-1969. [CrossRef] [PubMed]

88. Antony, G.; Zhou, J.; Huang, S.; Li, T.; Liu, B.; White, F.; Yang, B. Rice $x a 13$ recessive resistance to bacterial blight is defeated by induction of the disease susceptibility gene Os-11N3. Plant Cell 2010, 22, 3864-3876. [CrossRef]

89. Blanvillain-Baufumé, S.; Reschke, M.; Solé, M.; Auguy, F.; Doucoure, H.; Szurek, B.; Meynard, D.; Portefaix, M.; Cunnac, S.; Guiderdoni, E.; et al. Targeted promoter editing for rice resistance to Xanthomonas oryzae pv. oryzae reveals differential activities for SWEET14-inducing TAL effectors. Plant Biotechnol. J. 2017, 15, 306-317. [CrossRef]

90. Hutin, M.; Perez-Quintero, A.L.; Lopez, C.; Szurek, B. MorTAL Kombat: The story of defense against TAL effectors through loss-of susceptibility. Front. Plant Sci. 2015, 6, 535. [CrossRef]

91. Yu, Y.; Streubel, J.; Balzergue, S.; Champion, A.; Boch, J.; Koebnik, R.; Feng, J.; Verdier, V.; Szurek, B. Colonization of rice leaf blades by an African strain of Xanthomonas oryzae pv. oryzae depends on a new TAL effector that induces the rice nodulin-3 Os11N3 gene. Mol. Plant Microbe Interact. 2011, 24, 1102-1113. [CrossRef] [PubMed]

92. Li, T.; Liu, B.; Spalding, M.H.; Weeks, D.P.; Yang, B. High-efficiency TALEN-based gene editing produces disease-resistant rice. Nat. Biotechnol. 2012, 30, 390-392. [CrossRef] [PubMed]

93. Streubel, J.; Pesce, C.; Hutin, M.; Koebnik, R.; Boch, J.; Szurek, B. Five phylogenetically close rice SWEET genes confer TAL effector mediated susceptibility to Xanthomonas oryzae pv. oryzae. New Phytol. 2013, 200, 808-819. [CrossRef] [PubMed]

94. Boch, J.; Bonas, U.; Lahaye, T. TAL effectors-pathogen strategies and plant resistance engineering. New Phytol. 2014, $204,823-832$. [CrossRef]

95. Hutin, M.; Sabot, F.; Ghesquiere, A.; Koebnik, R.; Szurek, B. A knowledge-based molecular screen uncovers a broad spectrum OsSWEET14 resistance allele to bacterial blight from wild rice. Plant J. 2015, 84, 694-703. [CrossRef] [PubMed] 
96. Chu, Z.; Fu, B.; Yang, H.; Xu, C.; Li, Z.; Sanchez, A.; Park, Y.J.; Bennetzen, J.L.; Zhang, Q.; Wang, S. Targeting xa13, a recessive gene for bacterial blight resistance in rice. Theor. Appl. Genet. 2006, 112, 455-461. [CrossRef]

97. Quirino, B.F.; Normanly, J.; Amasino, R.M. Diverse range of gene activity during Arabidopsis thaliana leaf senescence includes pathogen-independent induction of defense-related genes. Plant Mol. Biol. 1999, 40, 267-278. [CrossRef] [PubMed]

98. Seo, P.J.; Park, J.M.; Kang, S.K.; Kim, S.G.; Park, C.M. An Arabidopsis senescence-associated protein SAG29 regulates cell viability under high salinity. Planta 2011, 233, 189-200. [CrossRef]

99. Mathan, J.; Singh, A.; Ranjan, A. Sucrose transport in response to drought and salt stress involves ABA-mediated induction of OsSWEET13 and OsSWEET15 in rice. Physiol. Plant. 2021, 171, 620-637. [CrossRef]

100. Ren, Y.; Huang, Z.; Jiang, H.; Wang, Z.; Wu, F.; Xiong, Y.; Yao, J. A heat stress responsive NAC transcription factor heterodimer plays key roles in rice grain filling. J. Exp. Bot. 2021, 72, 2947-2964. [CrossRef] [PubMed]

101. Lalonde, S.; Boles, E.; Hellmann, H.; Barker, L.; Patrick, J.W.; Frommer, W.B.; Ward, J.M. The dual function of sugar carriers. Transport and sugar sensing. Plant Cell 1999, 11, 707-726. [CrossRef] [PubMed] 